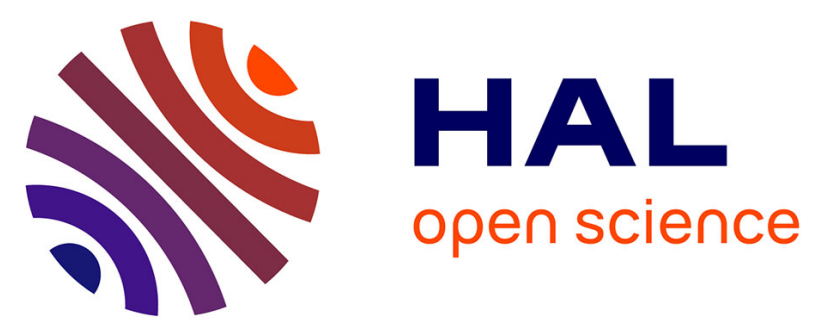

\title{
The usage of alternative splice sites in Mus musculus synaptotagmin-like 2 gene is modulated by cyclosporin A and FK506 in T-lymphocytes.
}

\author{
Laurent Mascarell, Rodolphe Auger, Jean M Kanellopoulos, Paolo
}

Truffa-Bachi

\section{To cite this version:}

Laurent Mascarell, Rodolphe Auger, Jean M Kanellopoulos, Paolo Truffa-Bachi. The usage of alternative splice sites in Mus musculus synaptotagmin-like 2 gene is modulated by cyclosporin A and FK506 in T-lymphocytes.. Molecular Immunology, 2007, 43 (11), pp.1846-54. 10.1016/j.molimm.2005.10.019 . pasteur-00161682

\section{HAL Id: pasteur-00161682}

https://hal-pasteur.archives-ouvertes.fr/pasteur-00161682

Submitted on 6 Aug 2007

HAL is a multi-disciplinary open access archive for the deposit and dissemination of scientific research documents, whether they are published or not. The documents may come from teaching and research institutions in France or abroad, or from public or private research centers.
L'archive ouverte pluridisciplinaire HAL, est destinée au dépôt et à la diffusion de documents scientifiques de niveau recherche, publiés ou non, émanant des établissements d'enseignement et de recherche français ou étrangers, des laboratoires publics ou privés. 


\title{
The usage of alternative splice sites in mus musculus synaptotagmin-like 2 gene is modulated by cyclosporin A and FK506 in T-lymphocytes
}

\author{
Laurent Mascarell $^{\mathrm{a}, *, 1}$, Rodolphe Auger ${ }^{\mathrm{b}, 1}$, Jean M. Kanellopoulos ${ }^{\mathrm{b}}$, Paolo Truffa-Bachi ${ }^{\mathrm{a}}$ \\ a Unité de Biologie des Populations Lymphocytaires, Institut Pasteur, 75724 Paris cedex 15, France \\ ${ }^{\mathrm{b}}$ Institut de Biochimie et Biophysique Moléculaire et Cellulaire, Université Paris XI, 91405 Orsay, France \\ Received 10 October 2005; accepted 28 October 2005 \\ Available online 10 January 2006
}

\begin{abstract}
Cyclosporin-A and FK506 block the calcineurin activity preventing the transcription of genes sharing NFAT-like binding sequences in their promoter region. We presently show that activation of murine T-cells in presence of these immunosuppressors results in the up-regulation of the synaptotagmin-like 2 gene. However, of the four known isoforms, only mRNAs encoding the a and $b$ isoforms accumulate. Two previously undected isoforms, each characterized by the retention of an intron, were found. The first, Slp2-e, includes exon 8 , intron 8 and exon 9 . The second, Slp2-f, is composed of exon 7, intron 7 and exon 8. Slp2-f has an open reading frame coding for a putative protein of 1229 amino acids sharing $47 \%$ identities with the human breast-associated antigen, SGA-72 M. In addition to the well-documented modulation of gene transcription, the two immunosuppressors also play a role in the choice of alternative splice sites on murine Slp2 pre-mRNA.
\end{abstract}

(C) 2005 Elsevier Ltd. All rights reserved.

Keywords: Immunosuppressive agents; Gene transcription; Messengers RNA; RNA Splicing; T-Lymphocytes

\section{Introduction}

Discrepancies between the number of genes, the cDNA libraries and the proteomics analyses indicate that alternative splicing mechanisms should operate to ensure the large protein diversity such as a given gene may produce large sets of proteins possessing common and unique sequences (reviewed in Modrek and Lee, 2002). Splicing alternatives have been described for many genes but the mechanisms regulating this machinery are not well understood (reviewed in Caceres and Kornblihtt, 2002; Modrek et al., 2001). Given the large number of tumors arising from unexpected alternative splicing, the analysis of the mechanisms involved in the control of this process may be an important step in the comprehension of tumorigenesis. Lymphoproliferative disorders and skin cancers are a common and dreaded complication in the clinical utilization of two immunosuppressors, cyclosporin A (CSA) and tacrolimus (FK506) (Thiel et

\footnotetext{
* Corresponding author at: Plateforme d'Immunologie, Stallergenes, 6 rue Alexis de Tocqueville, 92183 Anthony Cedex, France. Tel.: +33 155592516; fax: +330155592102 .

E-mail address: 1mascarell@ stallergenes.fr (L. Mascarell).

1 These authors have made equal contributions to this work.
}

al., 1994; Stewart et al., 1995). The targets of these molecules are the cyclophilins and the FKBPs (FK506-binding protein), for CSA and FK506, respectively. These complexes bind to calcineurin and prevent the activation of this phosphatase involved in many activation pathways (Crabtree, 1999). Several studies have revealed that activation of T-cells in the presence of CSA induces the synthesis of IL6 (Williamson et al., 1994), TGF- $\beta$ (Prashar et al., 1995), LAT (linker for T-cell activation) (Peters et al., 2000) and of hundreds of other proteins in vitro and in vivo (Mascarell et al., 2000; Mascarell and Truffa-Bachi, 2002; Mascarell and Truffa-Bachi, 2003). We have recently identified by representational differential analyses (RDA) some of the corresponding genes (Mascarell et al., 2004). Among these, we have detected the expression of the synaptotagmin-like 2 gene (Slp2) (Mascarell et al., 2004).

The alternative splicing of Slp2 mRNA produces four isoforms in the brain, where the gene is constitutively expressed (Fukuda et al., 2001). Since alternative splicing is regulated by a complex process involving, in addition to the spliceosome, the transcription machinery (reviewed in Caceres and Kornblihtt, 2002; Rosonina and Blencowe, 2002), we tested whether CSA and FK506 could affect the regulation of the alternative splicing pattern of Slp2 gene in T-cells. The present data show that only 
the Slp2-a and Slp2-b isoforms accumulate in large quantities in T-cells activated in presence of CSA or FK506. Strikingly, two previously undected isoforms, each characterized by the retention of an intron, were discovered. The first, denominated Slp2-e, includes exon 8, intron 8 and exon 9. Exon 7, intron 7 and exon 8 are joined in the second isoform, named Slp2-f, giving rise to an ORF of $3687 \mathrm{bp}$. Slp2 gene is not activated by an other immunosuppressor which does not target calcineurin suggesting that both Slp2 gene activation and the choice of alternative splicing sites of the corresponding mRNA are regulated by calcineurin.

\section{Materials and methods}

\subsection{T-cell activation}

T-cells were purified as previously described (Caceres and Kornblihtt, 2002). Cells were cultured in $2 \mathrm{ml}\left(2 \times 10^{6}\right.$ cells $\left./ \mathrm{ml}\right)$ in complete RPMI (RPMI 1640 (Life Technologies Inc., Grand Island, NY)) supplemented with $2 \mathrm{mM}$ L-glutamine, $50 \mu \mathrm{g} / \mathrm{ml}$ streptomycin, $50 \mathrm{U} / \mathrm{ml}$ penicillin, $5 \%$ heat-inactivated fetal calf serum, $5 \times 10^{-5} \mathrm{M}$ 2-mercaptoethanol. Two micrograms per milliliter of ConA (Sigma) were added at the onset of the culture. CSA, a kind gift of Novartis (France) was added at $1 \mu \mathrm{g} / \mathrm{ml}$ to one group of cells. Non-activated cells and CSAtreated non-activated cells were also cultured. Cells were placed in a humidified atmosphere of $5 \% \mathrm{CO}_{2}$ in air and recovered at selected times. Brain's mRNA was prepared as previously described (Liu et al., 1991).

\subsection{PCR analysis of the transcripts}

At selected times, $2 \times 10^{6}$ purified T-cells were lyzed in TRIzol reagent ${ }^{\circledR}$ (Gibco BRL, Grand Island, USA). cDNA was prepared using M-MLV reverse transcriptase (Invitrogen-Life Technologies, Cergy-Pontoise, France) as previously described (Liu et al., 1991). The conditions of PCR amplification were as following: $30-40$ cycles (as indicated in the figure legends): $30 \mathrm{~s}$ denaturation at $95^{\circ} \mathrm{C}, 30 \mathrm{~s}$ annealing at $55^{\circ} \mathrm{C}$ and $30-60 \mathrm{~s}$ extension at $72{ }^{\circ} \mathrm{C}$. Following electrophoresis on $1.5 \%$ agarose gel, the PCR products were visualized using a transilluminator.

The primers used for the amplification of the four known isoforms of the Slp2 gene are the following: Slp2-a: $5^{\prime}$-TCCCAAGCTACATTTGTTACA- $3^{\prime}$ (exon 1, position 41) and 5'-AAATGCGTCTCATACCAAAG-3' (exon 6 position 27501); Slp2-b: 5'-ACAGTCATTCAGCCCAAGT-3' (exon 8, position 33883) and $5^{\prime}$-GAAAGAAGAGCTGCTAGGAAA-3' (exon 9, position 36649); Slp2-c: 5'-CCCTCACTGCATCTTGACTA-3' (intron 9, position 38950) and 5'-TAGAAAAAGTCGCCAGAAGAC$3^{\prime}$ (exon 19, position 55902); Slp2-d: 5'-AGCTCTGAGACCCCTCTG-3' (intron 14, position 50445) and (exon 19, position 55902). 5'-TTAGAGACCATCGGCAAGGTA-3'. The position on the gene sequence is taken from the data on the gene bank for the murine Slp2 gene (accession number: Ensembl Gene ENSMUSG00000030616). The primers used for the revelation of specific isoforms are reported in the legends of the corresponding figures. $\beta$-Actin: $5^{\prime}$-CACGATTTCCCTCTCAGC- $3^{\prime}$,
5'-GCACCACACCTTCTACAA-3'. IL2: 5'-TGCTGACTCATCATCGA-3' ${ }^{\prime}, 5^{\prime}$-AGGATGGAGAATTACAG-3'

\section{Results}

\subsection{Preferential accumulation of Slp2-a and -b mRNA in T-cells activated in the presence of CSA}

We have previously reported that activation of T-cells in presence of CSA promotes the transcription of many genes among which we identified the Slp2 gene (Mascarell et al., 2004). The alternative splicing of Slp2 mRNA gives rise to four species of mRNAs sharing common exons, on one hand, and an exclusive set of individual exons on the other (Fukuda et al., 2001). To assess whether all the isoforms were expressed, PCR were performed with primers designed in order to uniquely amplify specific isoforms (see Section 2). mRNAs from T-cells activated for 4 and $24 \mathrm{~h}$ in presence or absence of CSA were used. Slp2-a mRNA is already detected in non-activated T-cells and is increased following activation in presence of CSA (Fig. 1). The Slp2-b mRNA isoform is untraceable in non-activated or ConAactivated T-cells, whereas activation in presence of CSA leads to its accumulation. Slp2-c and Slp2-d isoform were undetectable in T-cells activated in presence or absence of CSA; however,

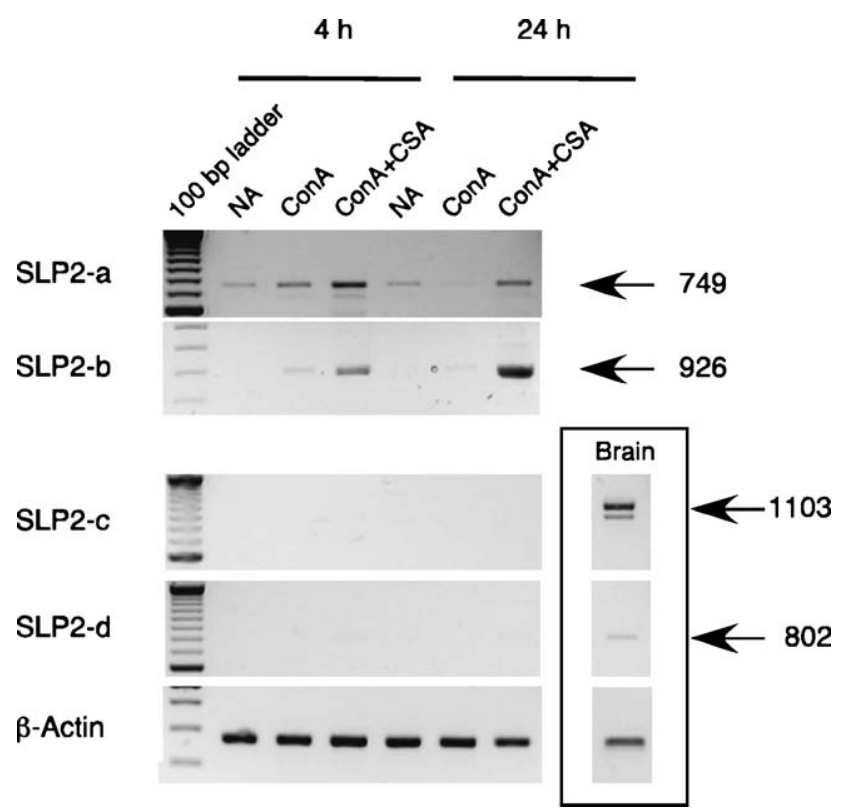

Fig. 1. T-cell activation in the presence of CSA increases Slp2-a and -b transcripts. Non-activated spleen cells (NA), or spleen cells activated with ConconavalinA (ConA) in the absence (ConA) or presence of CSA (ConA + CSA), were cultured for 4 and $24 \mathrm{~h}$. A group of cells was incubated with CSA alone (CSA). Following T-cell purification and RNA extraction, PCR (40 cycles) was performed with primers specific for synaptotagmin-2-like (Slp2) -a, -b, -c and -d isoforms, as described in Section 2. RNA prepared from brain cells was used and PCRs were performed using primers specific for the Slp2 isoforms -c and -d (inset). The amplified material was resolved by gel electrophoresis and the images were collected using a Vilber Lourmet transilluminator. $\beta$-Actin served as an internal standard for the quality and quantity of the mRNA preparation. The arrows show the size of the PCR products. The data are representative of three independent experiments. 
they are readily uncovered in the brain (Fukuda and Mikoshiba, 2001) attesting the efficacy of the primers used. These data show that Slp2 gene is transcribed in T-cells activated in presence of CSA and that CSA also regulate the level of accumulation of each individual transcript.

\subsection{CSA modulates the retention of introns in activated \\ T-cells giving rise to two new Slp2 isoforms}

The sequencing of the Slp2 clone originating from the RDA experiments (Mascarell et al., 2004) showed that the sequence is located between exon 8 and exon 9 and, therefore, it is not associated to any of the four Slp2 isoforms previously detected in brain (Fukuda et al., 2001). In order to analyze whether the transcript extended to the flanking exons, RT-PCR were carried out using different couples of primers located in intron 8 (group 1), exon 8 and intron 8 (group 2) and intron 8 and exon 9 (group 3), respectively (Fig. 2). cDNAs were prepared from splenic T-cells activated with ConA for 4 and $24 \mathrm{~h}$, in the presence or absence of the immunosuppressor. cDNAs from non-activated cells or from cells cultured in the presence of CSA alone served as controls. $\beta$-Actin mRNA accumulation is a control for mRNA quality and quantity. The prevention of IL2 mRNA increase show the effectiveness of the CSA treatment (Fig. 2). Amplified materials of the expected size accumulate with the three sets of primers used showing that the transcript detected in T-cells activated in presence of CSA extends into exon 8 and 9 (Fig. 2; only the $4 \mathrm{~h}$ data are represented). The PCR products were purified and sequenced. These sequences are identical to intron 8 sequence described in the gene bank (data not shown). PCRs were also prepared omitting the RT step. As shown in Fig. 2, no materials were detected in this condition demonstrating that the amplified materials does not originate from a genomic contamination.
When primers chosen in exon 7 , intron 9 or exon 10 were used in conjunction with any of the $5^{\prime}$ or $3^{\prime}$ end primers located in intron 8 , no amplified material was produced, suggesting that the new Slp2 mRNA, does not extend before exon 8 and behind exon 9 (data not shown). This isoform, named Slp2-e has an open reading frame corresponding to exon 8 and a stop codon at the $5^{\prime}$ end of intron 8; it represents thus a truncated form of Slp2-b.

During these analyses an amplified material of $1778 \mathrm{bp}$ was found in T-cells activated in presence of CSA with a set of primers located in exons 7 and 8 (Fig. 3, group 1). Exons 7 and 8 were never found associated in any of the previously described isoforms, exon 7 being specifically coupled with the Slp2-a isoform, whereas exon 8 is exclusively associated to the Slp2-b isoform (Fukuda et al., 2001). The existence of this new isoform was confirmed using two primers located in the flanking region of the alternatively spliced region, at the beginning and at the end of intron 7 and a primer specific for exon 8 (Fig. 3, group 2 and 3). Bands of the expected sizes were found with these primers. Such bands were almost undetectable in resting T-cells, or in activated T-cells or in Tcells cultured in presence of CSA alone. No amplification was observed when the RT step was omitted (data not shown). Combinations of primers located in exon 6 with primers situated in exon or intron 8 did not yield detectable materials showing that this new transcript does not extend into exon 6 and into intron 8 (data not shown). These results demonstrate that activation of T-cells in presence of CSA yields another Slp2 isoform that we named Slp2-f. The exon and the exon/intron organization of the previously known and the newly described Slp2 isoforms expressed in T-cell activated in presence of CSA are shown in Fig. 4; the alternative splice sites are also indicated.

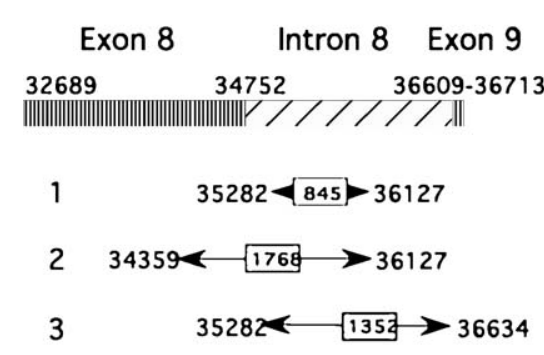

IL-2
$\beta$-Actin

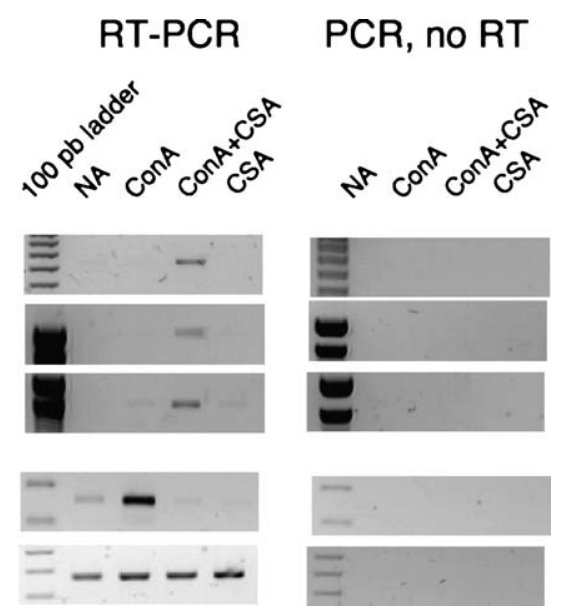

Fig. 2. Slp2-e mRNA accumulation by CSA in activated T-cells. Left panel: organization of the Slp2 gene in the region comprising exon 8 , intron 8 and exon 9 . The arrows indicate the position of the primers used for the amplification of the Slp2-f isoforms and the size of the PCR products. Right panel: cells activated in the presence or absence of CSA, as described in the legend of Fig. 1, were collected at 4 h. Following T-cell purification, RNA was prepared and PCRs (35 cycles) were performed with three couples of primers (their position on Slp2 gene and the size of the expected amplified material are indicated on the figure). Couple 1: $5^{\prime}$ CTCTTTTCTCTTTCCGTTTTC- $3^{\prime}$ and $5^{\prime}$-GAGAACTCCCCAGCTGA- $3^{\prime}$; couple 2: $5^{\prime}$-TGACTGGCCCATTGATAGATG- $3^{\prime}$ and $5^{\prime}$-GAGAACTCCCCAGCTGA3'; couple 3: 5'-CTCTTTTCTCTTTCCGTTTTC-3' and 5'-CAGAAGAAGAGCACAGCCCT-3'. Gels and analyses were performed as indicated in the legend of Fig. 1. Left panel: the RT step was omitted prior to PCR amplification. Amplification with primers specific for $\beta$-actin and IL 2 served as controls for the quality/quantity of the mRNA preparation and CSA immunosuppressive effect, respectively. The data are representative of three independent experiments. 


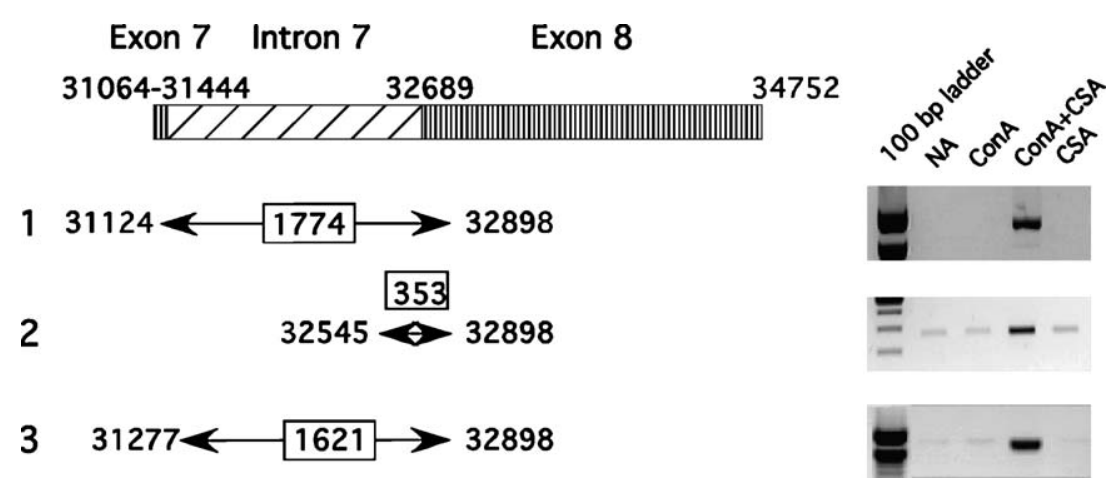

Fig. 3. Slp2-f mRNA accumulation by CSA in activated T-cells. Left panel: organization of the Slp2 gene in the region comprising exon 7, intron 7 and exon 8. The arrows indicate the position of the primers used for the amplification of the Slp2-f isoforms and the size of the PCR products. Right panel: cells activated in the presence or absence of CSA, as described in the legend of Fig. 1, were collected at $4 \mathrm{~h}$. Following T-cell purification, RNA was prepared and PCRs (35 cycles) were performed with three couples of primers (their position on Slp2 gene and the size of the expected amplified material are indicated on the figure). Couple 1: $5^{\prime}$-GCCTGAGCCATCACAGAC-3'; $5^{\prime}$-AAGCATTTTGCCTAAAGTCTC-3'. Couple 2: 5'-AACAAGTAAACACAATGATGGG-3'; $5^{\prime}$ AAGCATTTTGCCTAAAGTCTC-3'. Couple 3: 5'-ACACTATGTCATCCCTCCA-3'; $5^{\prime}$-AAGCATTTTGCCTAAAGTCTC-3'. Gels and analyses were performed as indicated in the legend of Fig. 1. The data are representative of three independent experiments.

Sequence analysis revealed that the Slp2-f isoform has an open reading frame of 3687 nucleotides beginning at the $5^{\prime}$ end of exon 7 , extending throughout intron 7 and terminating at the $3^{\prime}$ end of exon 8 (Fig. 5). This sequence encodes a putative protein of 1228 amino acids (Fig. 5). The nucleotidic/protein sequences boxed in red represent exon 7 and the beginning of exon 8 , respectively. No homologies were found with known nucleotidic/protein murine sequences. Nevertheless, the murine Slp2-f isoform shows high homology (47\% identities at the protein level) with a region of the human orthologue, Sytl2 gene (see supporting information). This region is located between exons 8 and 9 (mouse and human synaptotagmin-like 2 genes differ in the number of exons, 20 in the mice and 22 in the human). Strikingly, this region of the human Slp2 has also an open reading frame and a cDNA covering this region has been described (gene bank locus AY386362). Such an ORF is also conserved in rat and chimpanzee Slp2 gene orthologues (Fig. 6).

\subsection{Inhibition of the calcineurin-dependent activation pathway is implicated in the regulation of alternative splicing}

To assess whether the transcription of the Slp2 gene and the differential accumulation of the various transcripts was linked to the inhibition of the calcineurin pathway, two other immunosuppressants were used. FK506 acts as CSA on calcineurin, whereas rapamycin interferes with a later activation pathways originating from IL2 ligation to its high affinity receptor (reviewed in Rovira et al., 2000). Spleen cells were activated for 4 and $24 \mathrm{~h}$ in absence or presence of the various immunosuppressors. At the end of the stimulation, the T-cells were purified, and RT-PCR were carried out using appropriate couples of primers. IL2 mRNA accumulation was blocked by CSA and FK506 but not, as expected, by rapamycin (Fig. 7). Accumulation of the Slp2-a, -b, -e, and -f isoforms is observed in presence of CSA or FK506, but not of rapamycin suggesting a role of calcineurin in gene activation, as
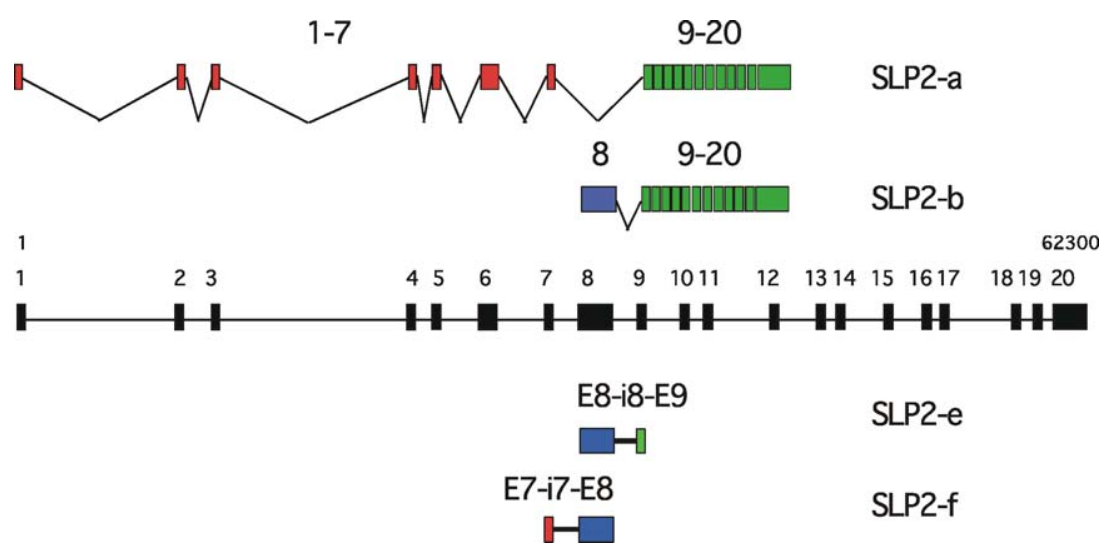

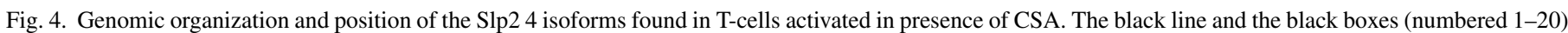

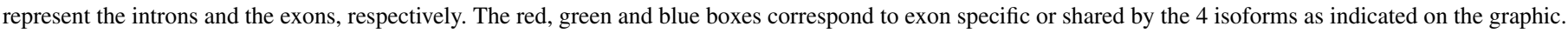
The alternative splicing sites used in the generation of the isoforms presently studied are shown in the inset and are numbered 1-6. 


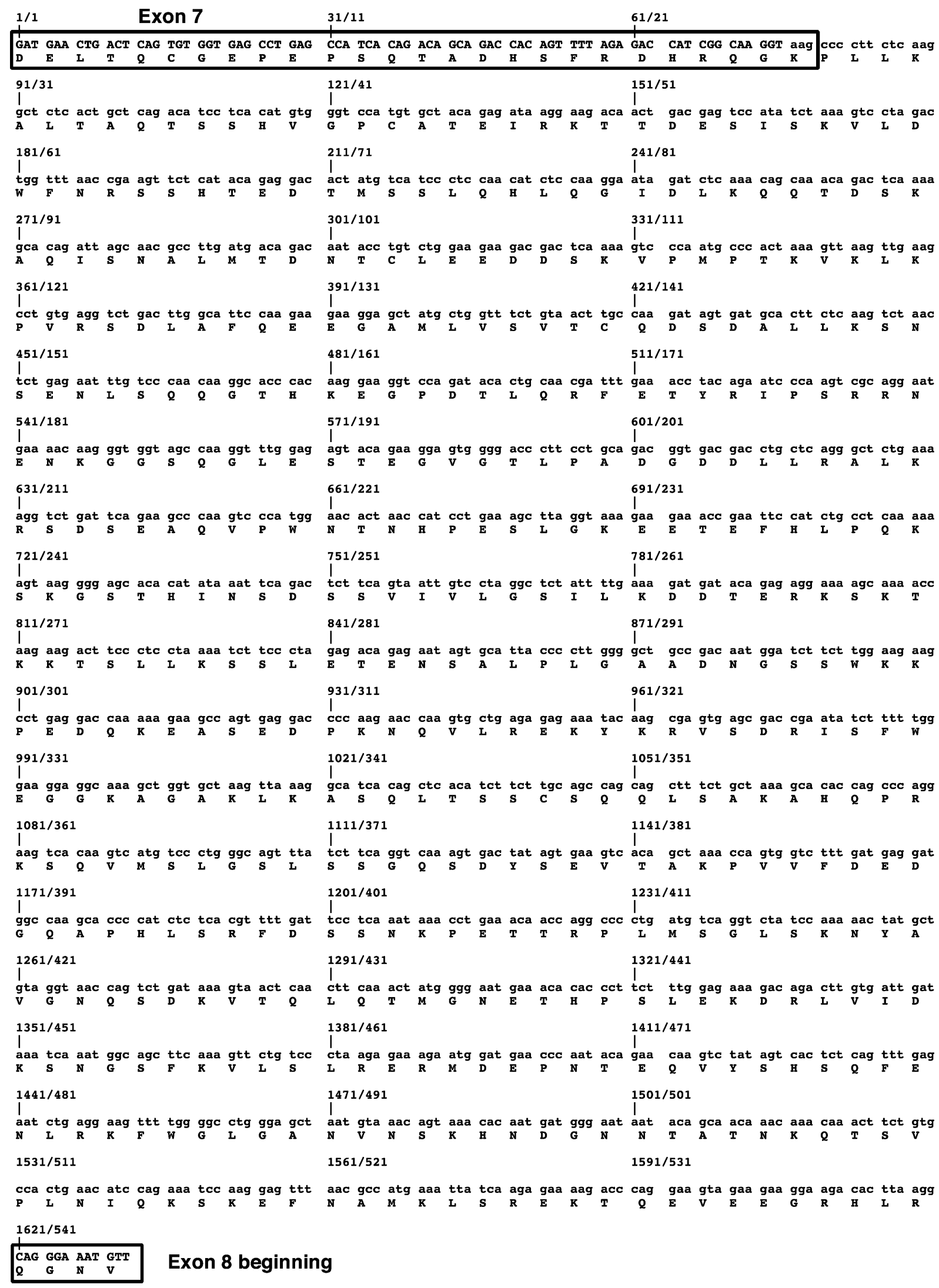

Fig. 5. Slp2-f encodes an open reading frame. Translation of the Slp2 gene sequence extending from the beginning of exon 7 to exon 8 . The amino acid sequence of exon 7 and the beginning of exon 8 are boxed. 

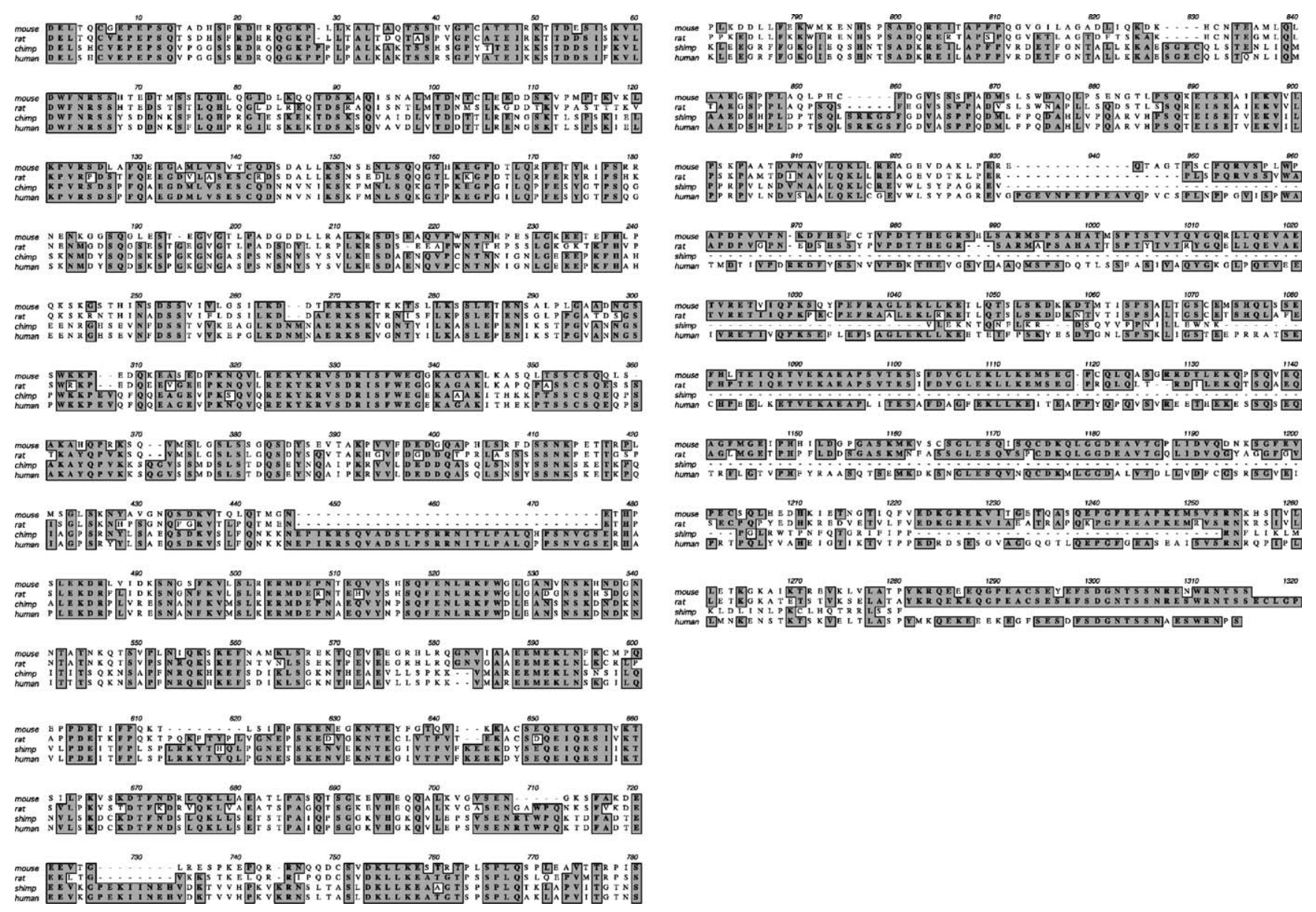

Fig. 6. Comparison of SLP2-f with rat, chimpanzee and human orthologue gene. The murine SLP2-f amino acid sequence was examined against rat, chimpanzee and human gene bank. Amino acids identities between the four species are boxed in gray.

already reported (Mascarell et al., 2000, 2004), and in the choice of alternative splicing sites.

\section{Discussion}

Triggering of T-cells in presence of CSA or FK506 provokes the transcription of the synaptotagmin-like 2 gene, an additional example of the antagonistic effects, i.e. gene blockade or gene up-regulation, of these two molecules on gene expression. Strikingly, these immunosuppressors also modulate the alternative splicing process. Of the four Slp2 species previously described in the brain (Fukuda et al., 2001), two accumulate in large quantities (Slp2-a and -b) and two are totally absent (Slp2-c and -d). Two other species, each characterized by the retention of an intron, were also detected. These isoforms originate from the region located between nucleotides 31069 and 36713 of the murine Slp2 gene (Unigene Mm.26751) that includes the sequence extending from the $5^{\prime}$ extremity of exon 7 to the $3^{\prime}$ end of exon 9. The Slp2-e isoform is made up by exon 8 (2064 bp), intron 8 (1856 bp), and exon 9 (104 bp) and lacks both the upstream (exons 1-7) and the downstream sequences (exons 10-20). A premature termination of translation at the $5^{\prime}$ end of intron 8 makes of this isoform encoding a protein of 678 amino acids a truncated form of Slp2-b. Slp2-f isoform covers exon
7 (78 bp), intron 7 (1545 bp) and exon 8 (2064 bp) and do not extend behind the $3^{\prime}$ end of this exon. Surprisingly, this sequence of 3687 nucleotides is an ORF potentially encoding a protein of 1229 amino acids.

mRNA editing takes place in the spliceosome, a ribonucleprotein complex composed of 300 distinct proteins and five RNAs (Jurica and Moore, 2003; Nilsen, 2003). Accurate splicing is accompanied by exon-intron junctions that are assured by weakly conserved intronic cis-elements (reviewed in Cartegni et al., 2002; Roca et al., 2003; Garcia-Blanco et al., 2004). The identification by the spliceosome components of the intron-exon boundaries also relies on sequences distinct from the splice sites that are present in exons and in introns. Finally, four functional regulatory elements located in exons and/or introns have been implicated in the choice of exon selection (reviewed in Jurica and Moore, 2003).

The synthesis of the Slp2-a, -b and of the two novel isoforms relies on the utilization, in various combinations, of six splice sequences (Fig. 4). Slp2-a originates from the splicing of the pre-mRNA at the sequences flanking exon 7 (Fig. 4, sites 1 and 2). This allows the association of exon 7 to exon 6 (and to the first 5 exons), on one side. Joining at the $3^{\prime}$ end results in the excision of exon 8 and to the junction to exon 9 , the downstream exons being joined by the utilization of the sequence at the $3^{\prime}$ 
$4 \mathrm{~h}$

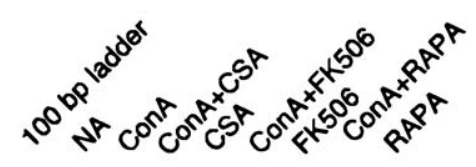

SLP2-a

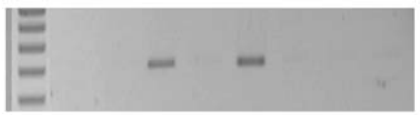

SLP2-b

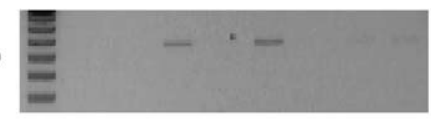

SLP2e

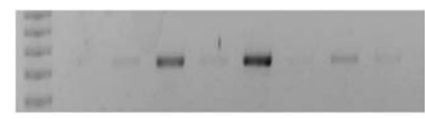

SLP2-f

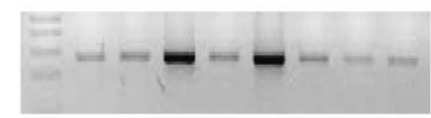

IL-2

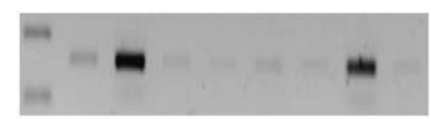

$\beta$-Actin

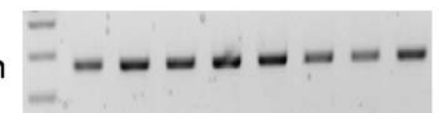

$24 \mathrm{~h}$
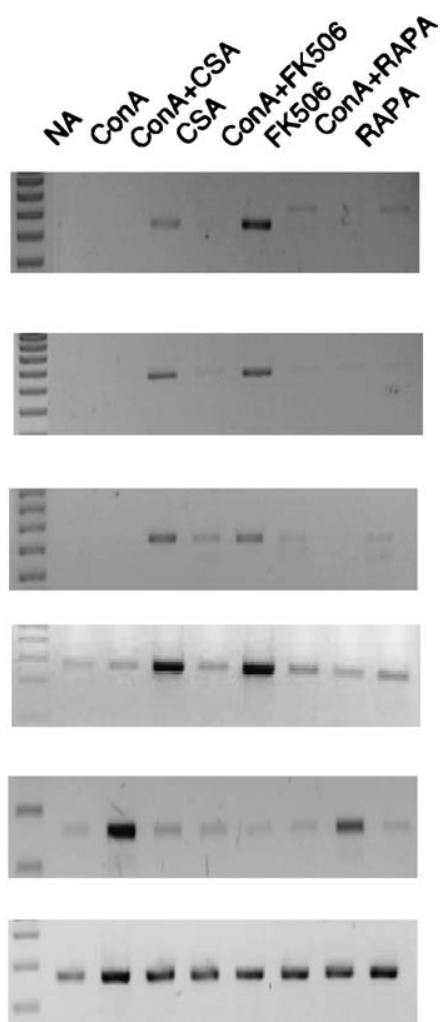

Fig. 7. Accumulation of mRNA encoding Slp2-a, -b, -e and -f isoforms is linked to the blockade of the calcineurin pathway. Spleen cells were activated with ConA, either alone (ConA), or in the presence of CSA (ConA + CSA), FK506 (ConA + FK506), or rapamycin (ConA + RAPA). Non-activated cells were cultured with CSA (CSA), FK506 (FK506), or rapamycin (RAPA). Following 4 and $24 \mathrm{~h}$ of activation, the cells were recovered and T-cells were purified. RT-PCRs (30 cycles) were performed using primers specific for IL2, Slp2-a, Slp2-b, Slp2-e and Slp2-f isoforms, and the amplified material was analyzed as described in the legend of Fig. 1. The data are representative of three independent experiments.

end of exon 9 (Fig. 4, site 6). The sequences flanking exon 8 are used for Slp2-b production. Splicing at the $5^{\prime}$ end precludes the junction with the upstream exons, whereas splicing at the $3^{\prime}$ end causes the junction to exon 9 and to the other downstream exons. For the two newly identified isoforms, the conventional sites are either used or skipped. The conventional sequence located at the $5^{\prime}$ end of exon 8 (site 3) is used for Slp2-e synthesis. However, the splicing sequence located at the $3^{\prime}$ end (site 4) is skipped by the spliceosome resulting in the junction of exon 8 to intron 8 and exon 9. This also provokes the termination of splicing and no downstream exons are linked to this isoform. For Slp2-f production, the $5^{\prime}$ end sequence of exon 7 (site 1) and the sequence located at the $3^{\prime}$ end of exon 8 (site 4 ) are used, the two other conventional sites ( 2 and 3 ) being skipped. This also results in the termination of the junction to upstream or downstream exons.

Are CSA and FK506 acting directly or indirectly on the spliceosome? A member of the cyclophilin family, USA-CyP, is part of a complex with two spliceosomal proteins involved in both steps of pre-mRNA splicing. It has been shown that association of CSA to USA-CyP inhibits the splicing efficiency leading to the accumulation of unspliced mRNA species (Horowitz et al., 2002). However, the simultaneous accumulation of transcripts encoding the classical (Slp2-a and -b) and the novel (Slp2-e and -f) isoforms in presence of CSA does not support the implication of USA-CyP. In addition, FK506 induces the accumulation of mRNA encoding both classical and novel isoforms. However, an FK506-binding protein (FKBP), sharing with USA-Cyp inhibitory splicing capacities, is not associated to the spliceosome (Jurica and Moore, 2003; Nilsen, 2003).

A target, common to CSA and FK506, but not to rapamycin, an immunosuppressor that does not alter the pattern of Slp2 isoforms expression, should be implicated in the modulation of the spliceosome machinery. Although structurally unrelated, both CSA and FK506 act on the calcineurin-dependent pathway blocking the antigen-induced T-cell proliferation (Liu et al., 1991, reviewed in Crabtree, 1999; Kiani et al., 2000). The association of CSA to cyclophilins, on one hand, and of FK506 to FKBPs, on the other hand, results in the formation of two distinct three-molecular complexes with calcineurin, complexes in which the enzymatic activity of calcineurin is blocked (Liu et al., 1991; Fruman et al., 1992). Both cyclophilins and FKBPs are ubiquitous proteins that are 10-100 times more abundant, in a mole/mole ratio, to the concentration of each immunosuppressor effectively blocking the calcineurin activity, the limiting factor being the calcineurin concentration (reviewed in Fruman et al., 1994). The resolution of the three-molecular complexes by $\mathrm{X}$-ray crystallography has definitely proved the model of action 
of CSA and FK506 (Mikol et al., 1994; Theriault et al., 1993; Kissinger et al., 1995). It is thus tempting to consider that the two immunosuppressors act on alternative splicing through the inhibition of calcineurin, an hypothesis substantiated by the lack of effect of rapamycin that also binds to FKBP but interferes with a biochemical pathways distinct from the calcineurin one (Albers et al., 1993).

Calcineurin is a key enzyme in T-cell activation. This phosphatase dephosphorylates different substrates, among which NFAT, provoking their translocation to the nucleus and consequently the activation of genes essential in T-cell proliferation and differentiation (Emmel et al., 1989, reviewed in Rao et al., 1997). Calcineurin is also implicated in the activation of other biochemical pathways related to the progression of Tlymphocytes in cell cycle (Sugimoto et al., 1997; Trushin et al., 1999; Shaywitz and Greenberg, 1999). The formation of threemolecular complexes between calcineurin and CSA-cyclophilin or FK506-FKBP inhibits the calcineurin activity and all the biochemical pathways linked to its activation. This precludes the expression of the genes having in their promoter region NFATconsensus sequences (Shibuya and Taniguchi, 1989; Jain and Valge-Archer, 1992). However, inhibition of calcineurin has also an up-regulating effect on the transcription of many genes: IL6 (Morton, 1999), TGF- $\beta$ (Khanna et al., 1994; Cotrim et al., 2003), LAT (Peters et al., 2000), CSTAD (Mascarell et al., 2004) and of hundreds, not yet identified, genes (Mascarell et al., 2000).

Slp2 gene is silent in T-cells but is actively transcribed in presence of CSA or FK506. This signifies that a set of transactivators either are induced or that pre-existing transactivators translocate to the nucleus upon calcineurin inhibition (Mascarell et al., 2000; Mascarell and Truffa-Bachi, 2003). Alternative splicing is regulated by a complex process involving the transcription machinery (reviewed in Caceres and Kornblihtt, 2002; Rosonina and Blencowe, 2002). Capping, splicing and cleavage/polyadenylation are highly coordinated in time and space. Notably, RNA polymerase II links mRNA synthesis with the splicing machinery throughout SR-proteins (Caceres and Kornblihtt, 2002). The relative abundance of these proteins and of the heterogeneous nuclear ribonucleoproteins (hnRNPs) plays a major role in the choice of the exons retained or excised (Fu, 1995; Graveley, 2000; Zahler et al., 1993), reviewed in Caceres and Kornblihtt, 2002). The different patterns of Slp2 isoform expression in brain and in T-cells may reflect tissular differences in SR-proteins. Alternatively, blockade of calcineurin provokes an imbalance in the relative abundance of the various SR-proteins and/or other factors of the splicing machinery allowing the production of both conventional and unconventional Slp2 mRNA isoforms.

Variability in splicing patterns is a major source of protein diversity from the genome. The function(s) of the four isoforms of Slp2 described in the literature are not still completely known. They share a $\mathrm{C} 2$ domain that potentially binds $\mathrm{Ca}^{2+}$. Slp2-a possesses, in addition, a Rab27A binding domain implicated in melanosome distribution in the cell periphery and regulating the morphology of melanocytes (Kuroda and Fukuda, 2004). Neither of the two newly described isoforms possesses these domains. Slp2-f encodes a protein that has no particular motifs or similarities with other murine proteins. However, Slp2-f shares high similarities with rat, chimpanzee and human orthologues. The conservation of an open reading frame across these species (Fig. 6) highly suggests that it has an important functional role.

Mutations affecting the regulation of alternative splicing have been implicated in human diseases (reviewed in Caceres and Kornblihtt, 2002; Garcia-Blanco et al., 2004). Many of these mutations affect canonical splice sites (Stenson et al., 2003). Regulation of alternative splicing contributes also to cancer, for example in mis-splicing of exon 18 in BRCA1 (Liu et al., 2001) or in tumor progression in the pathogenesis of prostate tumor (Yan et al., 1993). The human breast-associated antigen, SGA72M (locus AY386362), is located in human Slp2 gene (gene ID 54843). The matching mRNA contains exon 8 , intron 8 and exon 9 showing the occurrence of an intron retention phenomenon as found for murine Slp2-f. Strikingly, SGA-72 M possess an open reading frame that starts at the $5^{\prime}$ end of human exon 8 extending to the $3^{\prime}$ of exon 9 . This sequence encodes for a protein of 1788 amino acids, which shares $47 \%$ identities with the murine Slp2-f protein (Fig. 6 and data not shown). The finding that the retention of a coding intron is found associated to a tumor antigen in human and that an identical phenomenon occurs in the same gene in murine T-cells activated in presence of CSA is puzzling. CSA not only alters gene expression by blocking or inducing the transcription of numerous genes but it also affects sites of alternative splicing giving rise to the potential synthesis of novel proteins. It is tempting to speculate that the detrimental effect of CSA is linked to its capacity to alter normal splicing mechanisms.

\section{Acknowledgements}

Supported by funds from the Institut Pasteur and the Centre National de la Recherche Scientifique (URA 1961). R.A. and J.M.K. are supported by grants from the Fondation pour la Recherche Médicale and the Association pour la Recherche sur le Cancer. We authors are grateful to Philippe Glaser (Laboratoire de Génomique des Micro-Organismes Pathogènes, Institut Pasteur) for helpful advice and sequence realization. We thank Amanda Casrouge Unité de Génétique Humaine des Maladies Infectieuses, Faculté de Médecine Necker-Enfants Malades, Paris), for technical assistance on RDA experiment and Véronique Cadet-Daniel (Institut Pasteur) for technical support. We warmly thank Fabrice Confalonieri UMR8621, Institut de Génétique et Microbiologie Faculté des Sciences d'Orsay for critical review of the manuscript.

\section{References}

Albers, M.W., Williams, R.T., Brown, E.J., Tanaka, A., Hall, F.L., Schreiber, S.L., 1993. FKBP-rapamycin inhibits a cyclin-dependent kinase activity and a cyclin D1-Cdk association in early G1 of an osteosarcoma cell line. J. Biol. Chem. 268, 22825-22829.

Caceres, J.F., Kornblihtt, A.R., 2002. Alternative splicing: multiple control mechanisms and involvement in human disease. Trends Genet. 18, 186-193. 
Cartegni, L., Chew, S.L., Krainer, A.R., 2002. Listening to silence and understanding nonsense: exonic mutations that affect splicing. Nat. Rev. Genet. 3, 285-298.

Cotrim, P., Martelli-Junior, H., Graner, E., Sauk, J.J., Coletta, R.D., 2003. Cyclosporin A induces proliferation in human gingival fibroblasts via induction of transforming growth factor-beta1. J. Periodontol. 74, $1625-1633$

Crabtree, G.R., 1999. Generic signals and specific outcomes: signaling through $\mathrm{Ca}^{2+}$, calcineurin, and NF-AT. Cell 96, 611-614.

Emmel, E.A., Verweij, C.L., Durand, D.B., Higgins, K.M., Lacy, E., Crabtree, G.R., 1989. Cyclosporin-A specifically inhibits function of nuclear proteins involved in T-cell activation. Science 246, 1617-1620.

Fruman, D.A., Burakoff, S.J., Bierer, B.E., 1994. Immunophilins in protein folding and immunosuppression. FASEB J. 8, 391-400.

Fruman, D.A., Klee, C.B., Bierer, B.E., Burakoff, S.J., 1992b. Calcineurin phosphatase activity in lymphocytes- $\mathrm{T}$ is inhibited by FK-506 and Cyclosporin-A. Proc. Natl. Acad. Sci. U.S.A 89, 3686-3690.

Fu, X.D., 1995. The superfamily of arginine/serine-rich splicing factors. RNA 1, 663-680.

Fukuda, M., Mikoshiba, K., 2001. Synaptotagmin-like protein 1-3: a novel family of C-terminal-type tandem C2 proteins. Biochem. Biophys. Res. Commun. 281, 1226-1233.

Fukuda, M., Saegusa, C., Mikoshiba K, 2001. Novel splicing isoforms of synaptotagmin-like proteins 2 and 3: identification of the Slp homology domain. Biochem. Biophys. Res. Commun. 283, 513-519.

Garcia-Blanco, M.A., Baraniak, A.P., Lasda, E.L., 2004. Alternative splicing in disease and therapy. Nat. Biotechnol. 22, 535-546.

Graveley, B.R., 2000. Sorting out the complexity of SR protein functions. RNA 6, 1197-1211.

Horowitz, D.S., Lee, E.J., Mabon, S.A., Misteli, T., 2002. A cyclophilin functions in pre-mRNA splicing. EMBO J. 21, 470-480.

Jain, J., Valge-Archer, V.E., 1992. Rao A. Analysis of the AP-1 sites in the IL-2 promoter. J. Immunol. 148, 1240-1250.

Jurica, M.S., Moore, M.J., 2003. Pre-mRNA splicing: awash in a sea of proteins. Mol. Cell 12, 5-14.

Khanna, A., Li, B., Stenzel, K.H., Suthanthiran, M., 1994. Regulation of new DNA synthesis in mammalian cells by cyclosporine. Demonstration of a transforming growth factor beta-dependent mechanism of inhibition of cell growth. Transplantation 57, 577-582.

Kiani, A., Rao, A., Aramburu, J., 2000. Manipulating immune responses with immunosuppressive agents that target NFAT. Immunity 12, 359-372.

Kissinger, C.R., Parge, H.E., Knighton, D.R., Lewis, C.T., Pelletier, L.A., Tempczyk, A., et al., 1995. Crystal structures of human calcineurin and the human FKBP12-FK506-calcineurin complex. Nature 378, 641644.

Kuroda, T.S., Fukuda, M., 2004. Rab27A-binding protein Slp2-a is required for peripheral melanosome distribution and elongated cell shape in melanocytes. Nat. Cell Biol. 6, 1195-1203.

Liu, H.X., Cartegni, L., Zhang, M.Q., Krainer, A.R., 2001. A mechanism for exon skipping caused by nonsense or missense mutations in BRCA1 and other genes. Nat. Genet. 27, 55-58.

Liu, J., Farmer, J.D., Lane, W.S., Friedman, J., Weissman, I., Schreiber, S.L., 1991. Calcineurin is a common target of cyclophilin-cyclosporin-A and FKBP-FK506 complexes. Cell 66, 807-815.

Mascarell, L., Auger, R., Alcover, A., Ojcius, D.M., Jungas, T., Cadet-Daniel, V., et al., 2004. Characterization of a gene encoding two isoforms of a mitochondrial protein up-regulated by cyclosporin a in activated $\mathrm{T}$ cells. J. Biol. Chem. 279, 10556-10563.

Mascarell, L., Frey, H., Michel, F., Lefkovits, I., Truffa-Bachi, P., 2000. Increased protein synthesis after $\mathrm{T}$ cell activation in presence of cyclosporin A. Transplantation 70, 340-348.

Mascarell, L., Truffa-Bachi, P., 2002. Cyclosporin A therapy differently affects immunological-relevant gene expression following immunization. Immunol. Lett. 14, 137-143.

Mascarell, L., Truffa-Bachi, P., 2003. New aspects of cyclosporin A mode of action: from gene silencing to gene up-regulation. Mini Rev. Med. Chem. 3, 207-216.
Mikol, V., Kallen, J., Walkinshaw, M.D., 1994. X-ray structure of a cyclophilin B cyclosporin complex: comparison with cyclophilin A and delineation of its calcineurin-binding domain. Proc. Natl. Acad. Sci. U.S.A. 91, 5183-5186.

Modrek, B., Lee, C., 2002. A genomic view of alternative splicing. Nat. Genet. 30, 13-19.

Modrek, B., Resch, A., Grasso, C., Lee, C., 2001. Genome-wide detection of alternative splicing in expressed sequences of human genes. Nucleic Acids Res. 29, 2850-2859.

Morton, R.S., Dongari-Bagtzoglou, A.I., 1999. Regulation of gingival fibroblast interleukin-6 secretion by cyclosporine A. J. Periodontol. 70, 1464-1471.

Nilsen, T.W., 2003. The spliceosome: the most complex macromolecular machine in the cell? Bioessays 25, 1147-1149.

Peters, D., Tsuchida, M., Manthei, E.R., Alam, T., Cho, C.S., Knechtle, S.J., et al., 2000. Potentiation of CD3-induced expression of the linker for activation of $\mathrm{T}$ cells (LAT) by the calcineurin inhibitors cyclosporin A and FK506. Blood 95, 2733-2741.

Prashar, Y., Khanna, A., Sehajpal, P., Sharma, V.K., Suthanthiran, M., 1995. Stimulation of transforming growth factor-beta(1) transcription by cyclosporine. FEBS Lett. 358, 109-112.

Rao, A., Luo, C., Hogan, P.G., 1997. Transcription factors of the NFAT family-regulation and function. Annu. Rev. Immun. 15, 707-747.

Roca, X., Sachidanandam, R., Krainer, A.R., 2003. Intrinsic differences between authentic and cryptic $5^{\prime}$ splice sites. Nucleic Acids Res. 31, 6321-6333.

Rosonina, E., Blencowe, B.J., 2002. Gene expression: the close coupling of transcription and splicing. Curr. Biol. 12, R319-R321.

Rovira, P., Mascarell, L., Truffa-Bachi, P., 2000. The impact of immunosuppressive drugs on the analysis of T-cell activation. Curr. Med. Chem. 7, $1-20$.

Shaywitz, A.J., Greenberg, M.E., 1999. CREB: a stimulus-induced transcription factor activated by a diverse array of extracellular signals. Annu. Rev. Biochem. 68, 821-861.

Shibuya, H., Taniguchi, T., 1989. Identification of multiple cis-elements and trans-acting factors involved in the induced expression of human IL-2 gene. Nucleic Acids Res. 17, 9173-9184.

Stenson, P.D., Ball, E.V., Mort, M., Phillips, A.D., Shiel, J.A., Thomas, N.S., et al., 2003. Human gene mutation database (HGMD): update. Hum. Mutat. 21, 577-581.

Stewart, T., Tsai, S.C., Grayson, H., Henderson, R., Opelz, G., 1995. Incidence of de-novo breast cancer in women chronically immunosuppressed after organ transplantation. Lancet 346, 796-798.

Sugimoto, T., Stewart, S., Guan, K.L., 1997. The calcium/calmodulindependent protein phosphatase calcineurin is the major Elk-1 phosphatase. J. Biol. Chem. 272, 29415-29418.

Theriault, Y., Logan, T.M., Meadows, R., Yu, L.P., Olejniczak, E.T., Holzman, T.F., et al., 1993. Solution structure of the Cyclosporin-A cyclophilin complex by NMR. Nature 361, 88-91.

Thiel, G., Bock, A., Spondlin, M., Brunner, F.P., Mihatsch, M., Rufli, T., et al., 1994. Long-term benefits and risks of cyclosporin A (Sandimmun)-an analysis at 10 years. Transplant. Proc. 26, 2493-2498.

Trushin, S.A., Pennington, K.N., Algeciras-Schimnich, A., Paya, C.V., 1999. Protein kinase $\mathrm{C}$ and calcineurin synergize to activate IkappaB kinase and NF-kappaB in T lymphocytes. J. Biol Chem. 274, 22923-22931.

Williamson, M.S., Miller, E.K., Plemons, J., Rees, T., Iacopino, A.M., 1994. Cyclosporine a upregulates interleukin- 6 gene expression in human gingiva: possible mechanism for gingival overgrowth. J. Periodontol. 65, 895-903.

Yan, G., Fukabori, Y., McBride, G., Nikolaropolous, S., McKeehan, W.L., 1993. Exon switching and activation of stromal and embryonic fibroblast growth factor (FGF)-FGF receptor genes in prostate epithelial cells accompany stromal independence and malignancy. Mol. Cell. Biol. 13, 4513-4522.

Zahler, A.M., Neugebauer, K.M., Lane, W.S., Roth, M.B., 1993. Distinct functions of SR proteins in alternative pre-mRNA splicing. Science 260, 219-222. 